\title{
Mapping Rural Mobility in the Niakhar Area (Fatick Region, Senegal)
}

\author{
Alphousseyni Ndonky¹, Mouhamadou Moustapha Mbacké Ndour ${ }^{1}$, Ibrahima Ndiaye², \\ Richard Lalou ${ }^{3}$, Cheikh Tine ${ }^{4}$ \\ ${ }^{1}$ UFR Sciences de l'Ingénieur, Université de Thiès, Thiès, Sénégal \\ ${ }^{2}$ Ecole Supérieure d’Economie Appliquée, Université Cheikh Anta Diop de Dakar, Dakar, Sénégal \\ ${ }^{3}$ MERIT_UMR 216/IRD, Université Paris Descartes, Paris, France \\ ${ }^{4}$ Université Cheikh Anta Diop, Dakar, Sénégal \\ Email: ndonkyseyni10@gmail.com, aphousseyni.Ndonky@univ-thies.sn, moustapha.ndour@univ-thies.sn, \\ cheikhmouridee@yahoo.fr, richard.lalou@ird.fr, tinecheikh88@gmail.com
}

How to cite this paper: Ndonky, A. Ndour, M.M.M., Ndiaye, I., Lalou, R. and Tine, C. (2021) Mapping Rural Mobility in the Niakhar Area (Fatick Region, Senegal). Journal of Geographic Information System, 13, 65-82.

https://doi.org/10.4236/jgis.2021.131005

Received: January 13, 2021

Accepted: February 23, 2021

Published: February 26, 2021

Copyright $\odot 2021$ by author(s) and Scientific Research Publishing Inc. This work is licensed under the Creative Commons Attribution International License (CC BY 4.0).

http://creativecommons.org/licenses/by/4.0/

\section{(c) (i) Open Access}

\begin{abstract}
Despite the development of information and communication technologies, mobility still remains an important factor in the development of the social capital, by promoting social interactions. However, rural African populations face more difficulties getting around than city dwellers. In addition, studies on mobility in Africa are relatively weak. In rural African areas, this ignorance of mobility is even more important. It is necessary to identify the characteristics and the spatial structure of mobility flows before starting any reflection on solutions, particularly in terms of spatial allocation of transport resources. Our main objective is to map the current movement flows in the Niakhar area. We chose to use the cartographic approach to analyze mobility flows. The data come from a survey carried out in 2018, as part of the French Institute of Research for Development (IRD) Niakhar Atlas project. For the data analysis, we used 4 methods: dominant flux method, net flux calculation method, directional mean statistics and areal interpolation. The results revealed differences in mobility behavior depending on the season and in space, and the existence of three dominant centers: Ngayokhème, Diohine and Toucar. They also made it possible to highlight the main directions of the flows and the scalar fields of mobility.
\end{abstract}

\section{Keywords}

Rural Mobility, Polarization, Attractivity, Dominant Flow, Dominant Center, Area Interpolation, Displacement Field 


\section{Introduction}

The development of means of transport has increased the mobility capacity of populations and exchanges at the global level [1]. At the same time, the unequal distribution of resources (infrastructure, equipment and basic services) in the areas has increased the mobility needs of populations [2]. Despite the development of information and communication technologies, mobility still remains an important factor in the development of social capital, by promoting social contacts [3]. It allows people to access the equipment, services and jobs available in their area. As a structuring factor of territories, mobility makes it possible to account for discriminating processes, the relationship of populations to space and to reveal the level of socio-spatial integration.

However, studies on mobility in Africa are relatively weak. In rural African areas, that weakness is even greater. However, rural populations face more difficulties getting around than city dwellers. These mobility constraints are linked to various factors, including isolation, the state of communication channels, the lack of organized transport system, the often high cost of transport and the very low motorization of households. Those obstacles, combined with the prevailing poverty in these rural areas [4], considerably hinder the mobility capacity of rural populations. It is important to know the characteristics and the spatial structure of mobility flows before starting any reflection on solutions, particularly in terms of spatial allocation of transport resources. Indeed, the Niakhar area is a heterogeneous space from all points of view [5] and this heterogeneity can generate differences in mobility behavior.

Several studies have been carried out [6] [7] [8] [9] [10] to analyze the mobility. Admittedly, these studies are important, since they have made it possible to understand the socio-economic behavior of mobility and to reveal the spatial distribution of populations' movements, but they are insufficient. Indeed, they do not sufficiently take into account the spatial dimension, which is nevertheless very important for understanding mobility, the spatial allocation of transport equipment and services, and the fight against spatial disparities. The scale of data analysis is often arbitrary. The zoning used does not capture the process underlying the data, since the zones are often different in size and shape. So the results may simply be zoning artefacts. This makes their use for demand modeling and transport planning problematic. Moreover, concerning the specific case of the Niakhar area, so far, there is no study concerning the mapping of mobility flows.

In view of all these observations, we have chosen to use the cartographic approach to analyze rural mobility flows in the Niakhar area.

Our main objective is to map the current mobility flows in the Niakhar area. This involves in particular revealing the dominant flows and centers, the attractiveness and flow fields. To achieve this goal, we have followed four steps. The first consisted in determining the dominant flows and centers, the second in measuring attractiveness. In the third, we measured the polarization. The fourth step allowed us to determine the flow fields. 
In this study, we are interested in rural mobility, considered as the set of current trips made in rural areas to carry out activities. Indeed, everyday travel is necessary to accomplish social (wedding/baptism, visits from friends/relatives...) and economic (shopping/sales, work...) activities. This type of travel is becoming more and more important with the development of production tracks and weekly markets in rural areas, particularly that of Niakhar. In addition, it should be noted that long-term displacements in the Niakhar zone are outside the Niakhar zone, that is to say in other regions of Senegal, in particular that of Dakar. However, we are interested in movement within the Niakhar area. Mobility in our discussion associates all the travel flows of individuals during the last month preceding the day of the survey, the reasons for these trips and the means of transport used.

The data come from a survey carried out in 2018, as part of the Niakhar Atlas project of the IRD. For data analysis, we used 4 methods. These are firstly the dominant flux method proposed by [11] and the net flux calculation method [12], used respectively to measure dominant fluxes and attractiveness. Next, the directional mean statistic [13] [14] was used to measure flux polarization (flux vector field). Finally, the use of area interpolation [15] made it possible to determine the scalar flux field.

\section{Material and Method}

\subsection{Study Zone}

Located in the northern part of the department of Fatick (Fatick region), the Niakhar area is between $14^{\circ} 3^{\prime} 46^{\prime \prime} \mathrm{N}, 16^{\circ} 39^{\prime} 20^{\prime \prime} \mathrm{W}$ and $14^{\circ} 27^{\prime} 26^{\prime \prime} \mathrm{N}, 16^{\circ} 34^{\prime} 17^{\prime \prime} \mathrm{W}$. Bounded to the north by the department of Bambey (Diourbel region), to the west by the Mbour department (Thiès region), to the south by Fatick and to the east by Patar commune, consists of 30 villages divided between the communes of Ngayokhéme and Diarrére (Figure 1). Sahelo-Sudanese type, its climate is characterized by the alternation of two seasons (rainy season and dry season). In 2013 , its population was 44,994 inhabitants, with a density of 221.6 inhabi$\operatorname{tants} / \mathrm{km}^{2}$ [16]. This population is very young, because in 2012, young people under the age of 20 represented $53 \%$ of the total.

\subsection{Data}

The data used come from the survey on rural mobility carried out by IRD in 2018. Our survey plan was done taking into account the differences in social and cultural characteristics of the population of the study area and integration of the specific geographic (spatial) dimension of this area. In fact, we can note a social and spatial heterogeneity of the Niakhar zone and an interlocking of administrative meshes. In total, two criteria (constraints) guided the methodological choices: respect for the socio-demographic diversity of the Niakhar area, taking into account the heterogeneity of the rural space. Only the use of the finest mesh proposed by the administrative grid of the Niakhar zone (hamlet allowing an 


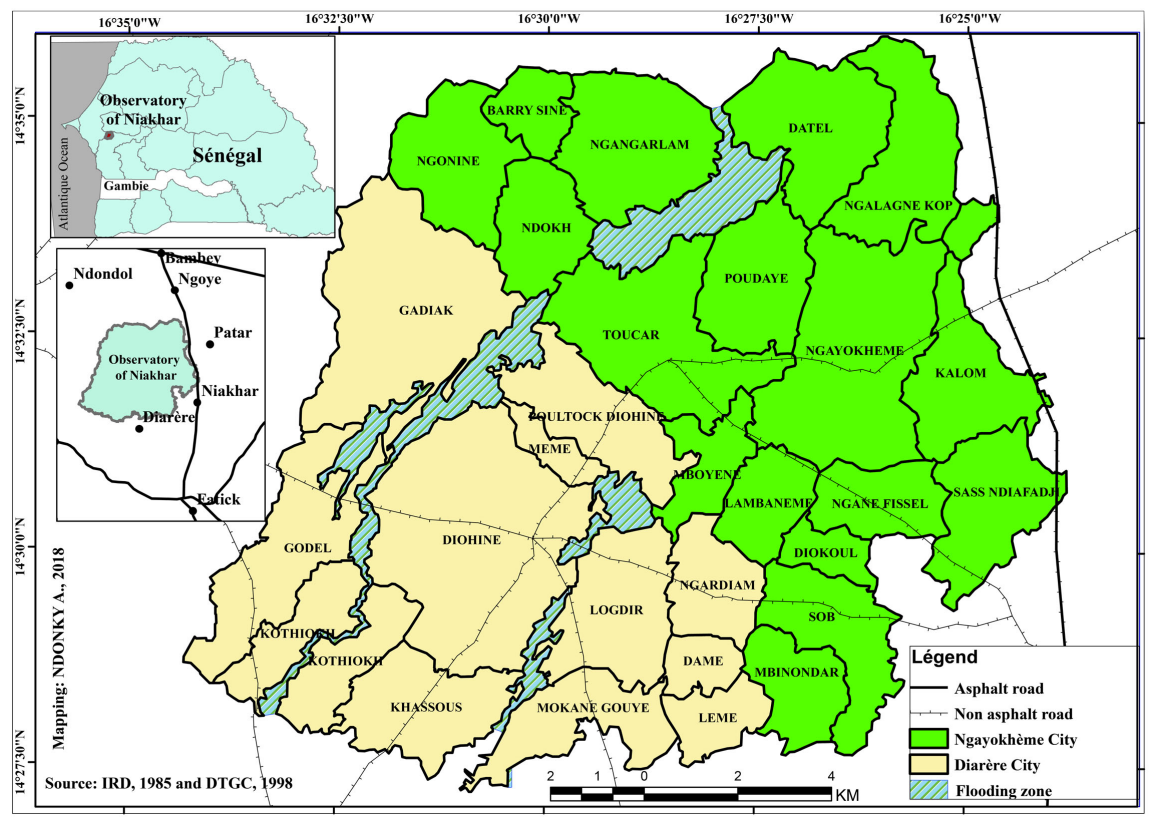

Figure 1. Study area.

exhaustive statistical treatment of the Niakhar zone) makes it possible to better understand this heterogeneity. The hamlet is the smallest administrative division unit in the Niakhar zone located below the village mesh. It is often homogeneous from a socio-demographic and spatial point of view, due to its small size.

The number of people to be surveyed is based mainly on the proportion of people aged 6 and over moving outside their village of residence. As this proportion is not known, to calculate the size of the sample, we will use the following formula:

$$
n=D * 0.25 * t 2 / e^{2}
$$

with:

$n=$ sample size of working people;

$D=$ sounding effect fixed at 2.5 ;

$e=$ Margin of error fixed at $5 \%$;

t2: $95 \%$ confidence level corresponding to 1.96 .

The calculation gives a minimum total sample size of 884 individuals. To increase the power of the test, we increased the total sample size to 900 .

The target population includes individuals aged 6 and over. Given the absence of an updated sampling frame, this could not be identified by random selection before the survey. Faced with this situation, we carried out a multi-stage cluster survey. Each hamlet is defined as a cluster. Thus, a random selection at the following degrees: hamlet, household and individuals, was carried out according to rigorous procedures and guaranteeing the random nature of the selection. In the first degree, we randomly drew the hamlets, 90 in total. In each hamlet, 10 households were selected and in each household, only one individual was chosen for the survey. Figure 2 illustrates the spatial distribution of the selected hamlets. 


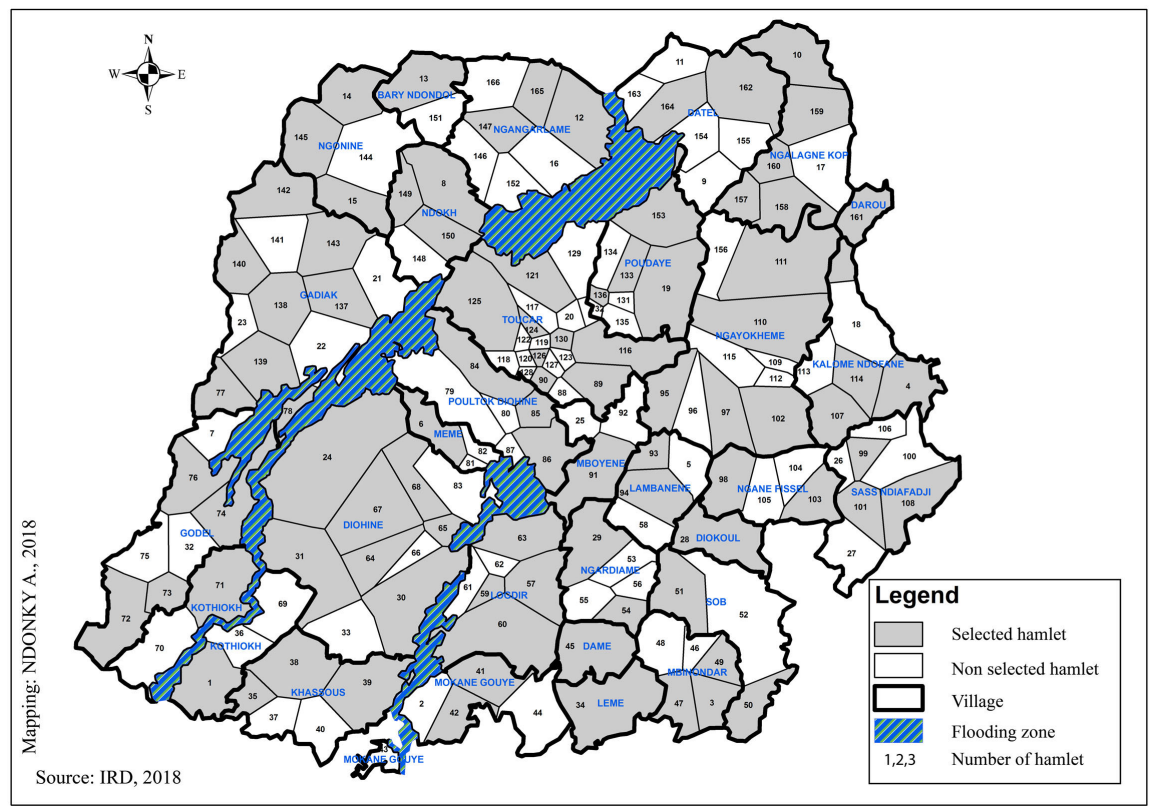

Figure 2. Hamlets selected for the survey.

The information collected during the survey relates to the socio-demographic characteristics of the household and of the individual surveyed, the places, means and reasons for travel (during the last 30 days preceding the survey) over two periods (dry season and summer season. rains). The choice of these two periods is justified by the fact that the possibilities and the travel routes often differ according to the season.

\subsection{Data Processing and Analysis Strategy}

The statistical processing of the data collected is done using CS Pro and Stata software. Geoprocessing, mapping and spatial analysis were done by ArcGIS and Quantum GIS software.

Our analysis includes 4 major steps: determination of the dominant flows and centers, measurement of attractiveness, mapping of the vector fields of observed flows and finally mapping of the scalar fields of estimated flows.

To determine the dominant fluxes and centers, the dominant flux method proposed by [11] was adopted. This method consists in representing at most one flow at the start of each spatial entity and offers the possibility of locating the main direction of the flows towards the dominant (center) zone. A zone A is said to be "dominant" of zone B when A receives the greatest flux from $\mathrm{B}$ and $\mathrm{A}$ receives more flux than $B$ [17]. A zone $A$ is said to be "dominated" by zone $B$ when $\mathrm{A}$ transmits the greatest flow towards $\mathrm{B}$ and $\mathrm{B}$ receives more flow than $\mathrm{A}$. Thus the use of flow classes (thresholds) becomes more relevant than proportional variations to make the flow map more readable. The great difficulty with which this method is confronted is the choice of the threshold beyond which the flow must be represented. The solution proposed by [18] is to take the mean of the flows as the threshold value. Another solution, proposed by [19], is to choose 
a certain percentage of dominant flows. Due to the strong asymmetry of the data in favor of low flows, we adopted the solution proposed by [19], by retaining a threshold of $5 \%$.

However, this method of dominant flows does not allow the measurement of attractiveness, which is nevertheless very essential for the description of mobility flows in the space.

To measure attractiveness, an attractiveness index was calculated for each village by making, for each of them, the balance/total volume of flows ratio. In order to summarize the information in a simple and efficient way, we have combined on a single map the total volume of flows exchanged and the attractiveness index. We can then locate the most important poles, attractive centers and repulsive places in space.

Admittedly, the two methods make it possible to describe the mobility flows, but they do not offer the possibility of apprehending the direction of the mobility flows, which is however very important for characterizing the movements in the space.

The use of directional mean statistics made it possible to measure the polarization of mobility flows. This method is based on Tobler's idea according to which each flow can be represented by a vector linking an origin point and a destination point and comprising a norm proportional to the number of flows exchanged [20]. The vector sum of the flows originating in a place produces a vector with an angle that corresponds to the average direction of these flows. The norm of this vector gives additional information on the intensity of the spatial orientation and the polarization of the fluxes emitted by the mean direction. The equation for the Linear Mean Directional (LMD) statistic is as follows:

$$
\mathrm{LMD}=\arctan \sum_{i=1}^{n} \sin \theta_{i} / \sum_{i=1}^{n} \cos \theta_{i}
$$

with $\theta_{i}=$ the directions of a series of polylines from the same origin [21].

That statistics is used to calculate the circular variance which indicates the degree of variation of the individual directions around the mean direction. Its value is between 0 and 1 . The smaller it is (close to 0 ), the more the input vectors have very similar directions and the higher the level of polarization. When it is larger (close to 1), then the input vectors have very different directions and the polarization level low. The circular variance equation (CirVar) is as follows:

$$
\operatorname{CirVar}=1-\frac{\sqrt{\left(\sum_{i=1}^{n} \sin \theta_{i}\right)^{2}-\left(\sum_{i=1}^{n} \cos \theta_{i}\right)^{2}}}{n}
$$

with $n=$ sample size [21].

We used the inverse of this variance to calculate the polarization index. The higher the index value, the stronger the polarization. So reading it will be easier.

The methods used so far have produced interesting results. However, they do not allow the representation of scalar flux fields, which are very important in the analysis of movements in the space. 
To map the scalar flux fields, we often use point interpolation methods. We can note, for example, the weighted average (or inverse distance) method, trend surface analysis, kriging [22] [23]. Certainly these methods are interesting for representing the specific phenomenon on a continuous surface. However, they have limitations with regard to the zonal layout data, as is the case in this study. For all these reasons, we chose to use the area interpolation method. The latter makes it possible, from the zonal implantation data, to produce a prediction surface (smoothed data) and errors, as well as to re-aggregate the data at the scale of the target polygons [15].

The overall approach for choosing the methods used is summarized in Figure 3. This figure highlights the complementarity of the methods used. So, the combination of all these methods allows to produce rich and complementary results.

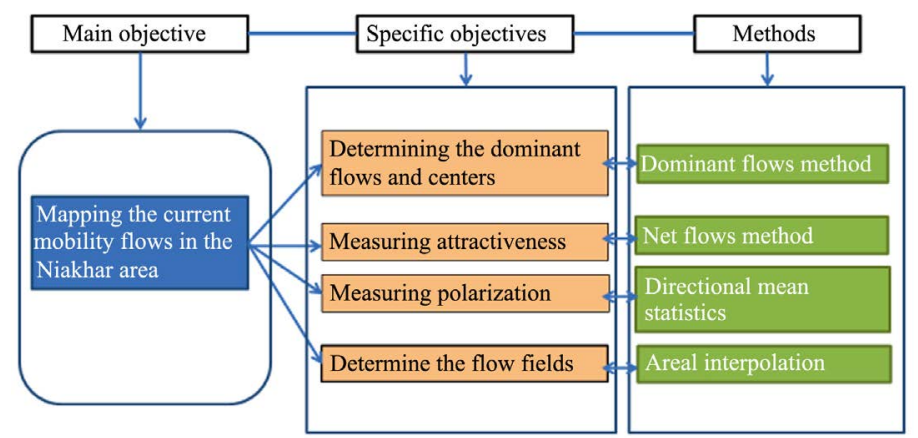

Figure 3. Global methodological approach.

\section{Results}

\subsection{Types of Centers and Dominant Flows}

The map of the dominant wintering centers and flows (Figure 4) is produced

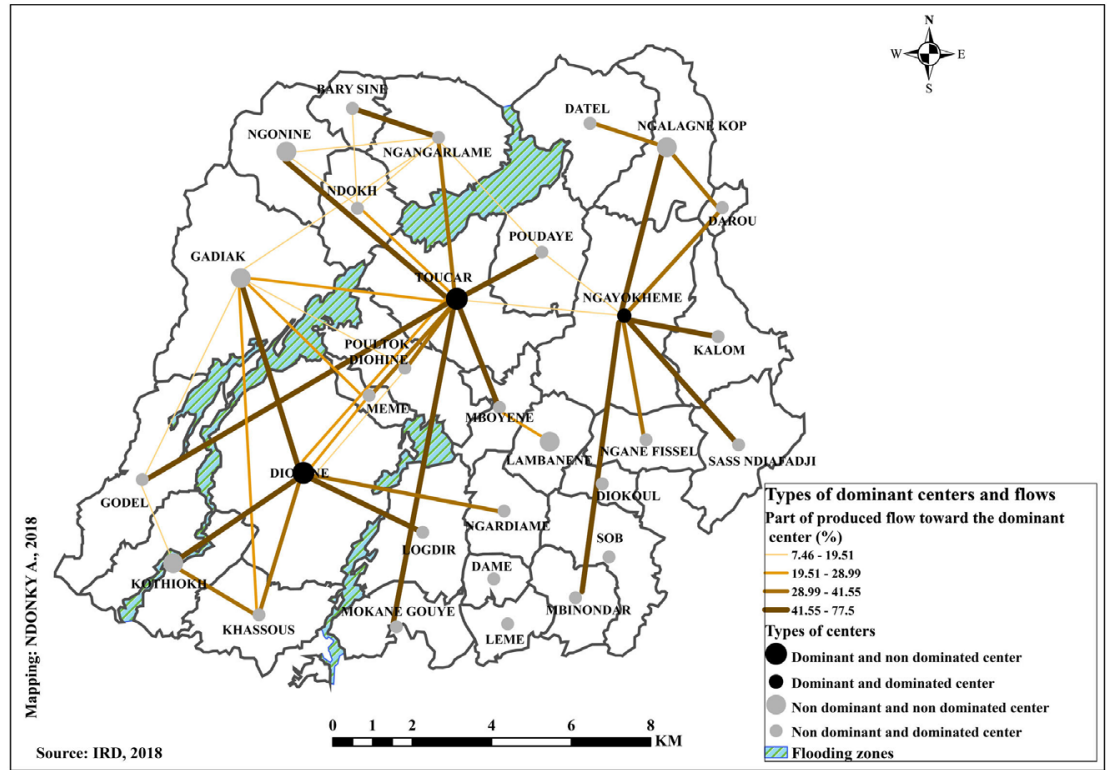

Figure 4. Dominant flows and centers during wintering. 
from 30 villages. On this map, we can observe non-dominated dominant centers which constitute main poles corresponding to the villages of Diohine and Toucar. They are complemented by a dominated dominant center which is a secondary pole receiving as many dominant flows as they emit; this is the village of Ngayokhème. The dominated centers are rather emitting localities which are distributed in a dispersed manner in space. There are two sub-categories: non-dominant centers not dominated and dominated non-dominant centers. The first sub-category includes 5 villages including 3 located in the north (Gadiak, Ngonine and Ngalagne Kop). The other two villages in this sub-category are Lambanène (center) and Kothiokh (south-west). The second sub-category is made up of villages that can be found almost everywhere, but more markedly in the south-east. Even if we observe the same dominant centers not dominated in the dry season and in wintering, nevertheless differences are to be noted (Figure 5). In the dry season, we can notice the emergence of 2 dominant centers dominated in the north: Ngonine and Ngangarlam and 2 non-dominant, non-dominated centers in the south-east: Dame and Sob. Figure 6 shows the spatial distribution of the dominant center and flow types of the average of the two seasons. We note the existence of a single dominant center not dominated in Diohine and two dominant centers dominated in Toucar and Ngayokhème. These centers polarize the main movement flows in the area. The secondary flows are polarized by the non-dominant, non-dominated centers that are found mainly in the south-east (Logdir, Dame, Sob) and north (Gadiak, Ngonine and Ngalagne Kop). The dominated non-dominant centers are distributed in a dispersed manner in space.

The analysis of the mobility flows for each of the two seasons and for the average of the two seasons produced rich and complementary results. Indeed, it

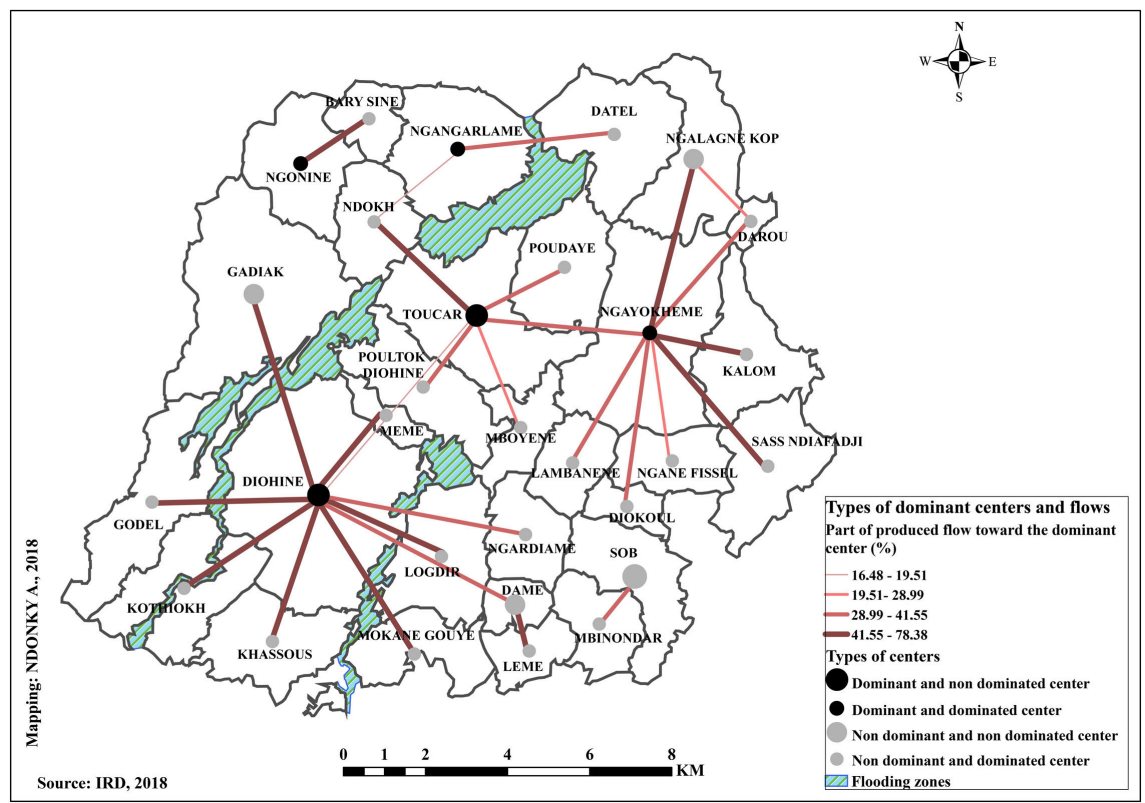

Figure 5. Dominant flows and centers in the dry season. 


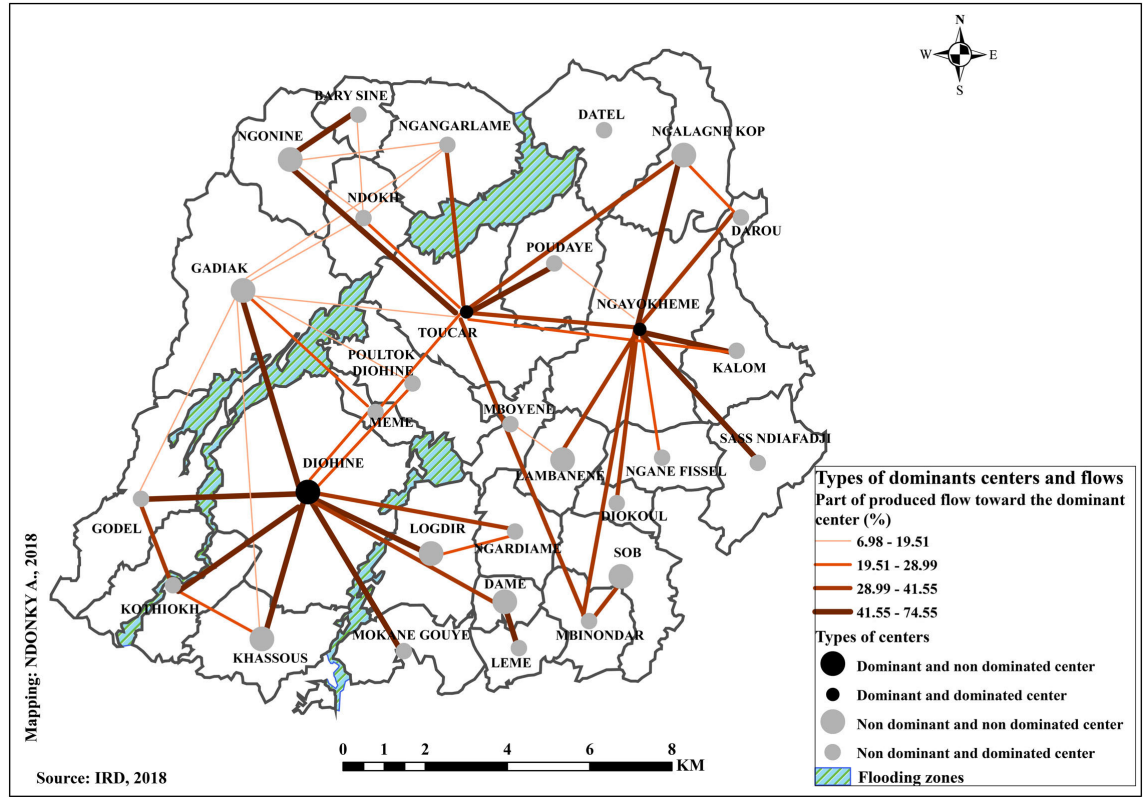

Figure 6. Average dominant flows and centers.

showed the differences in mobility behavior of the populations of the Niakhar zone in the space and according to the season.

\subsection{Attractiveness of Mobility Zones}

Attractiveness was measured at the scale of the 30 villages in our study area, in order to have more robust data. The space of the Niakhar zone is very unevenly attractive (Figure 7). The most attractive areas in the winter season are the villages of Diohine, Toucar, Sob, Ngayokhème and Ngonine. Among these villages, we can note those which are characterized by large flow volumes (Diohine, Toucar, Ngayokhème) and others which have low volumes (Sob and Ngonine). The most repulsive areas are those with very negative net migration. They concern in particular the villages of Darou, Ndokh, Poultok Diohine, Meme, Ngardiame which emit more flows than they receive. Those villages often have very low flow volumes (Figure 7).

Figure 8 shows the spatial distribution of attractiveness levels and flow volumes in the dry season. In general, flow volumes have increased compared to those observed in the winter season, particularly in the villages of Ngonine, Diohine, Toucar, Ngayokhème. Even if the spatial distribution structure of attractiveness levels remains broadly the same as in the winter season, there are, however, differences linked to intensity. Attractiveness has generally declined in intensity, and more particularly in the villages of Diohine, Toucar, Sob and Ngonine; this decline mainly affected the largest villages (Figure 8). On the other hand, in some places like Datel and Polultock Diohine, the attractiveness has increased.

Analysis of the map of attractiveness and flow volumes for the average of the two seasons shows differences from each of the two seasons (Figures 7-9). In 


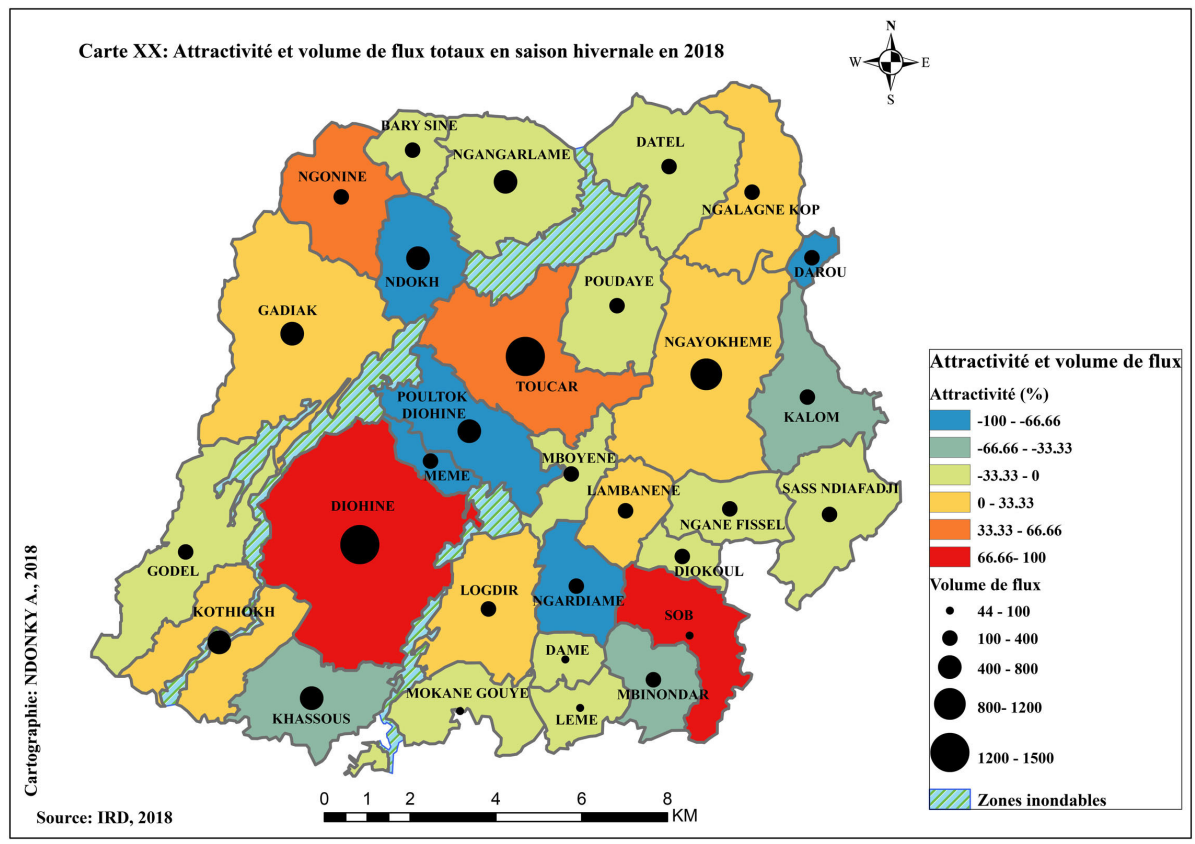

Figure 7. Attractiveness during wintering.

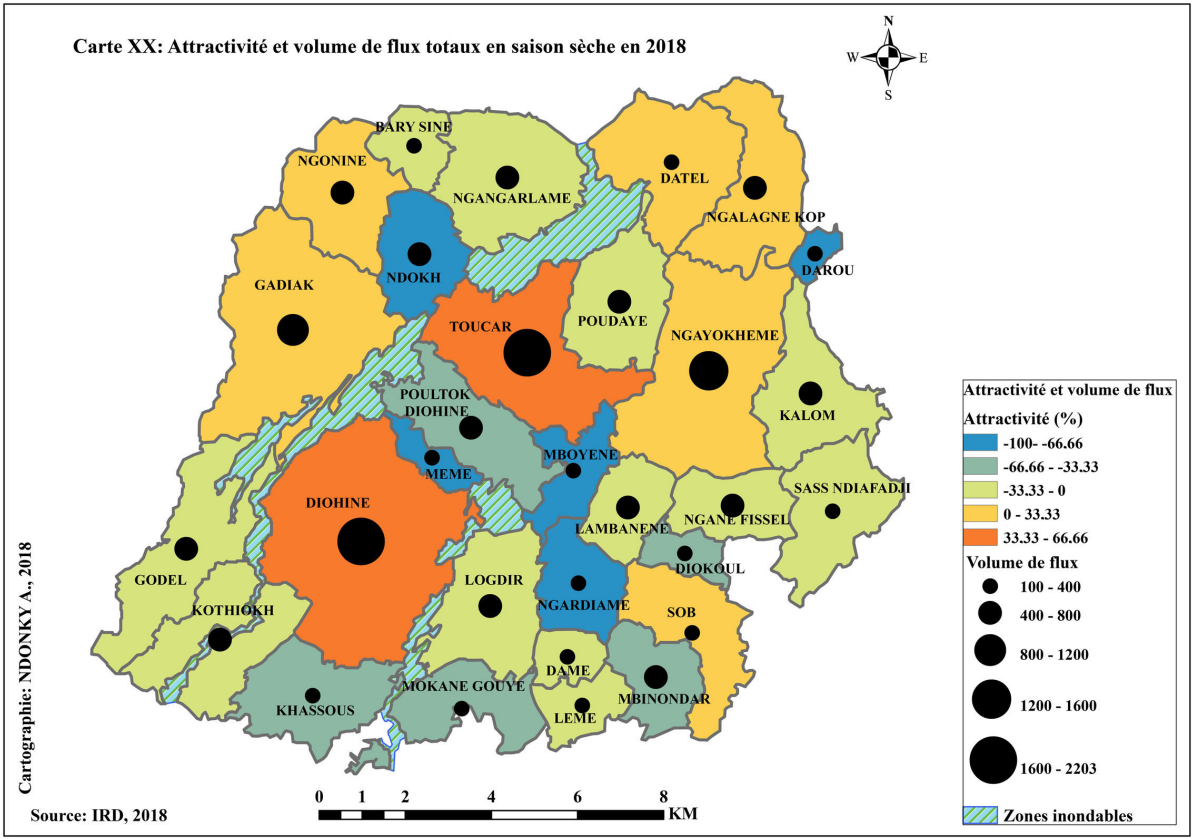

Figure 8. Attractiveness in the dry season.

fact, we can note that the levels of attractiveness have increased compared to those observed in the dry season, especially in the villages of Diohine, Sob and Lambanène. On the other hand, the level of attractiveness of Mokane Ngouye has decreased compared to that noted in the winter season. The spatial distribution of flow volumes more closely resembles that observed in the dry season.

These results therefore show differences in the movement behavior of populations in space and depending on the season. 


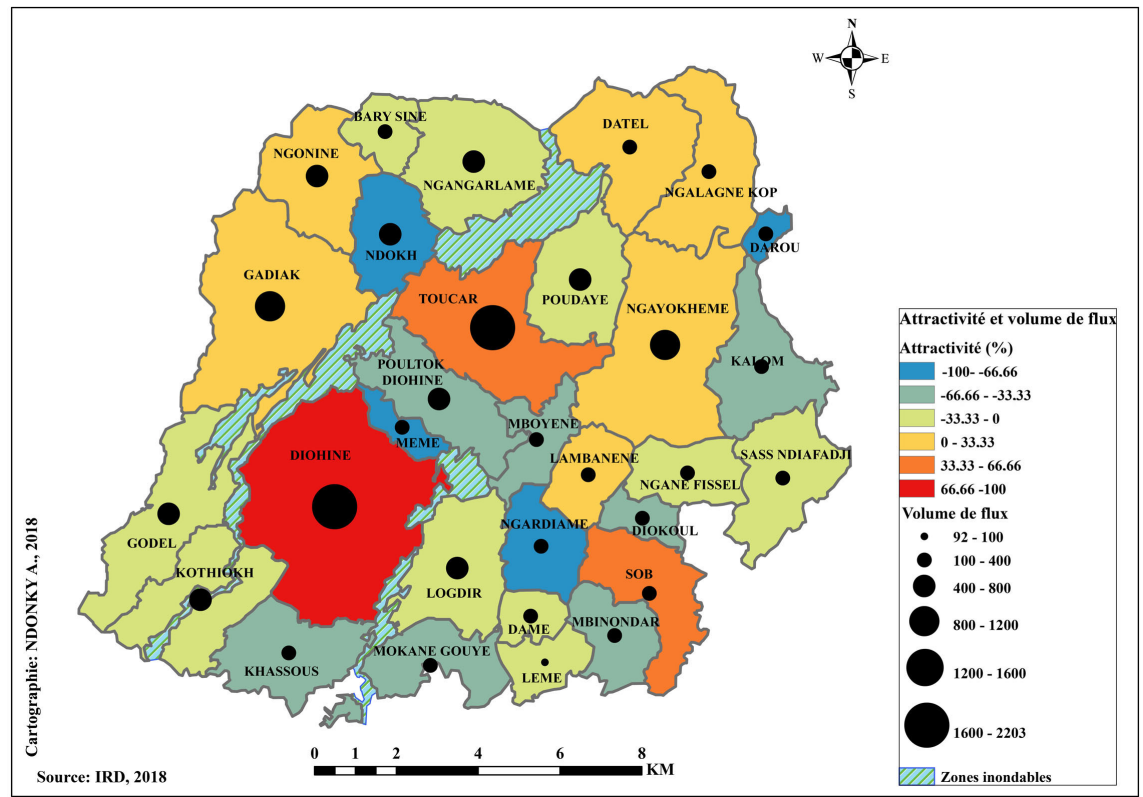

Figure 9. Attractiveness on average.

\subsection{Displacement Fields}

\subsubsection{Vector Fields of Observed Displacements}

Figure 9 and Figure 10 show the vector fields of movements observed respectively in wintering and in the dry season. In general, we can observe that Toucar, Ngayokhème and Diohine, the largest villages in the area, polarize the most displacement flows within the Niakhar area. The results also show that the flows are more polarized in wintering than in the dry season (Figure 10 and Figure 11). The most polarized flows come from the villages located on the outskirts of the area. We can note, for example, the flows coming from the villages of Godel, Khassous, Sob, Kothiokh. Those flows are all the more polarized as we are in wintering. On the other hand, flows from villages located in the center of the zone are less polarized.

\subsubsection{Scalar Fields of Estimated Emitted Flows}

To check the quality of the prediction, we use variographic analysis and cross-validation statistics. Variographic analysis involves changing the parameters of the model until $90 \%$ of the empirical covariances (blue crosses) fall within the confidence interval (in red) (Figure 12). Thus in the dry season, as in wintering, $91.12 \%$ of these covariances fall within the confidence interval (Figure 12 and Figure 13), which shows the good quality of the prediction (well-adjusted interpolation model).

The cross-validation statistics of the spatial interpolation model give a weighted root mean square close to 1.2 in the dry season and 1.1 in wintering, values close to 1 (ideal value for a well-fitted model). This confirms the results of the variographic analysis.

Since the predicted (estimated) data is valid, we will now present the results. Figure 14 and Figure 15 show the scalar fields of the emitted flows. They 


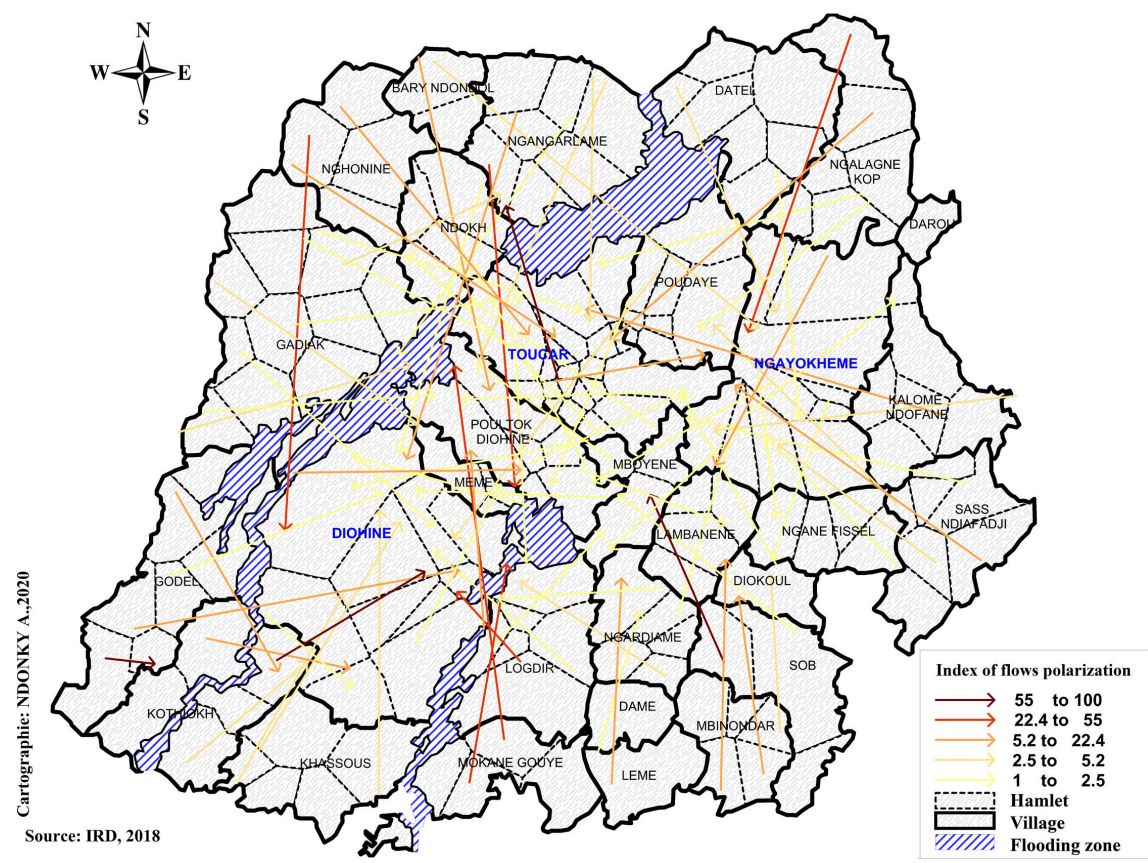

Figure 10. Vector field of intra-zone movements observed during wintering.

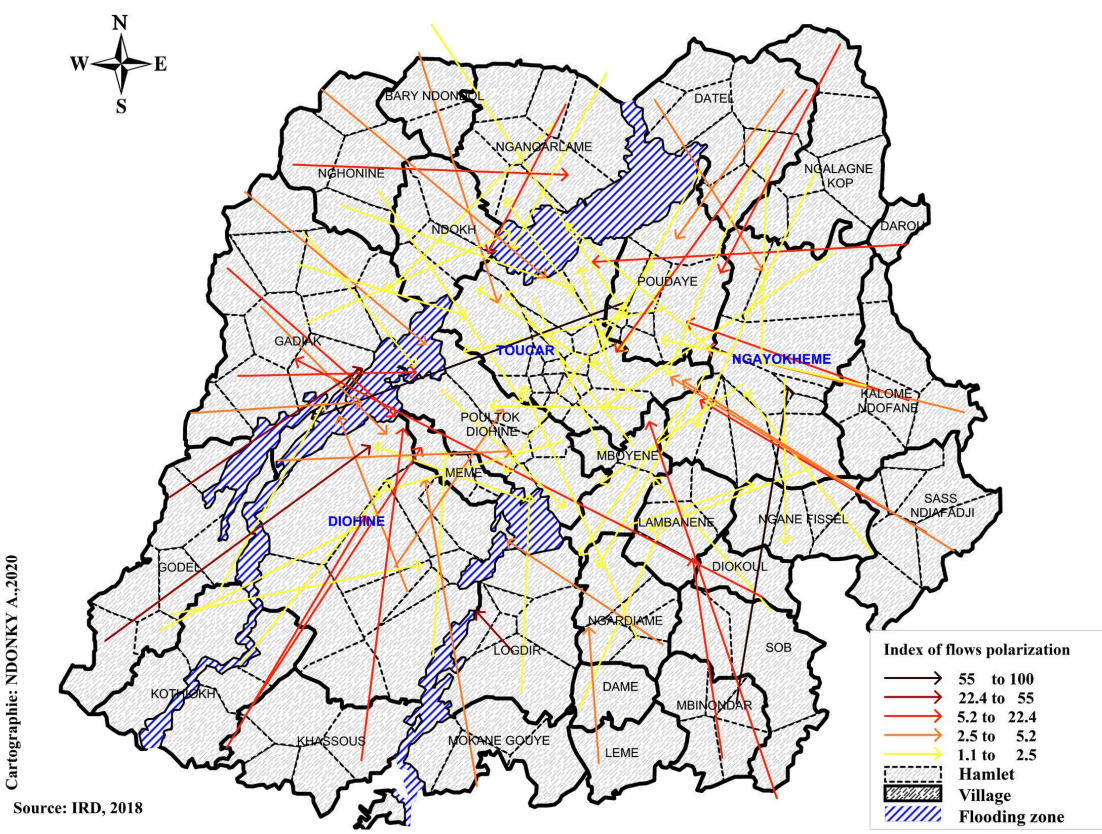

Figure 11. Vector field of intra-zone movements observed in the dry season.

indicate areas with high flux emission and those with low original flux. Thus the high emission zones are found in the villages of Bary Sine, Mboyenne, Poultok-Diohine, Poudaye, Diokoul, etc.

Areas of low emission are located in the villages of Ngalagne Kop, Diohine, Sob, Sas Ndiafadj, Darou, etc. There is a strong heterogeneity of the area. This heterogeneity can be observed even within the same village. Thus, the village of Logdir includes areas of high emission and those of very low flux emission which 


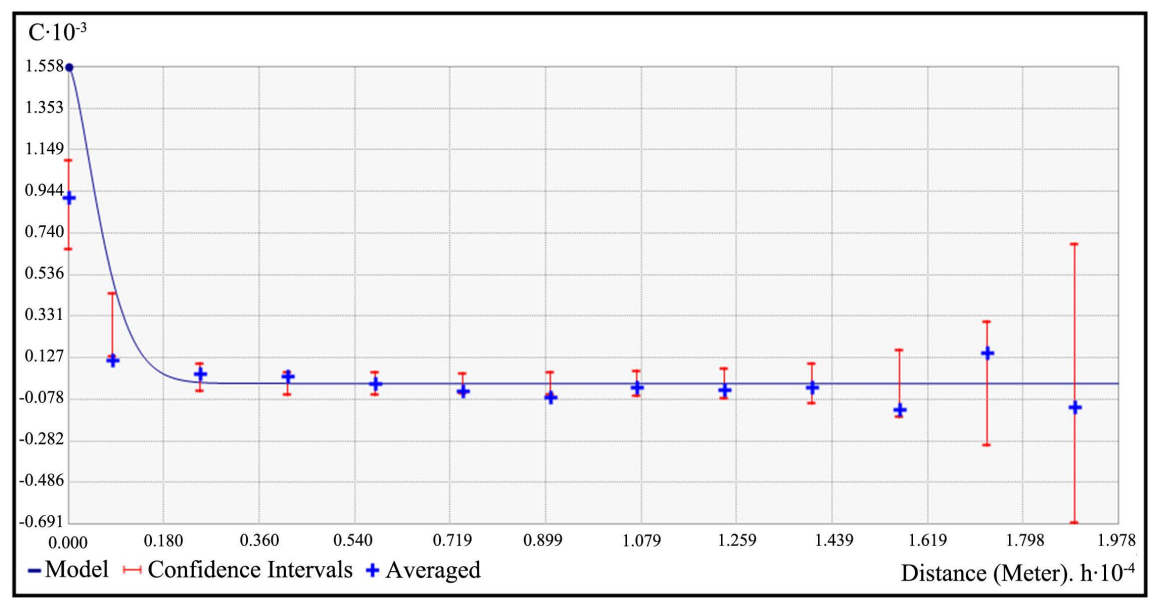

Figure 12. Variogram in the dry season.

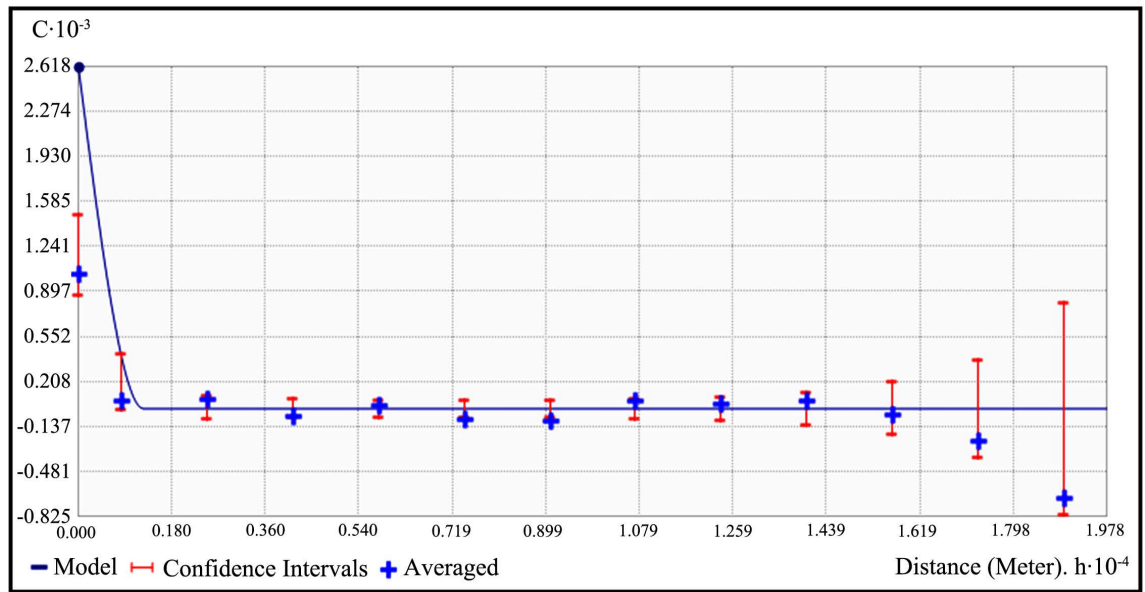

Figure 13. Variogram in wintering.

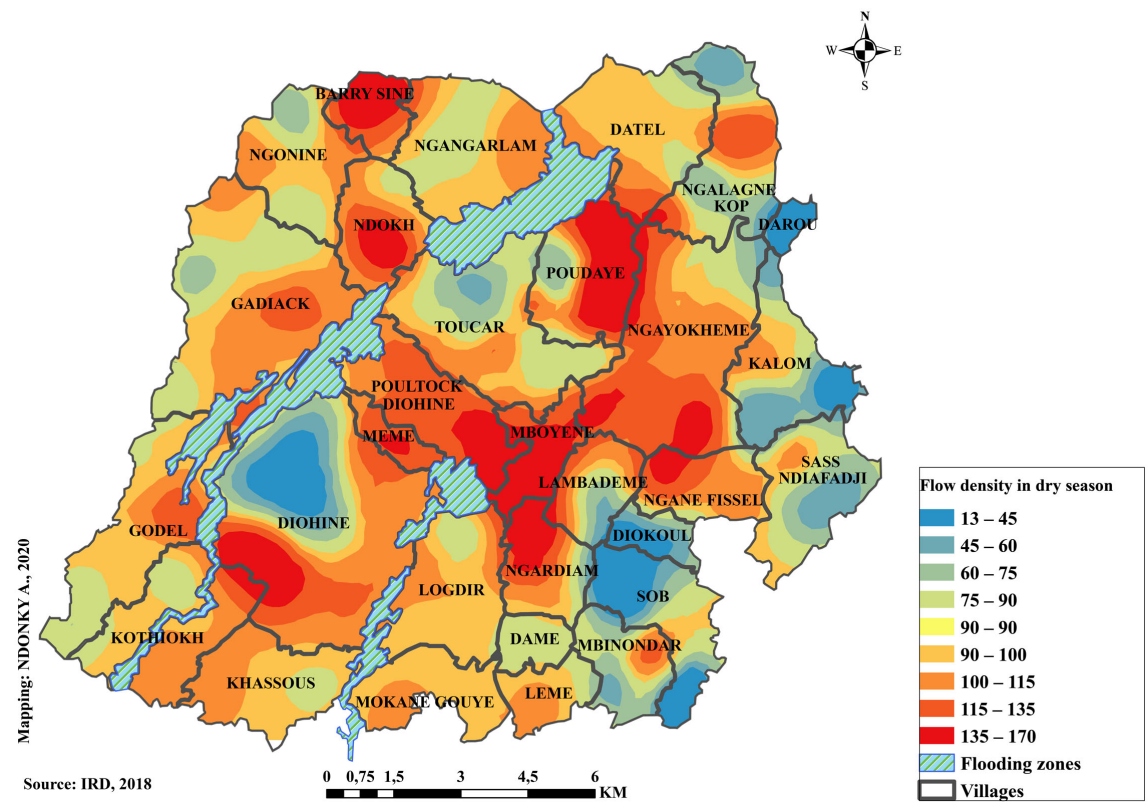

Figure 14. Prediction surface for flows in wintering. 


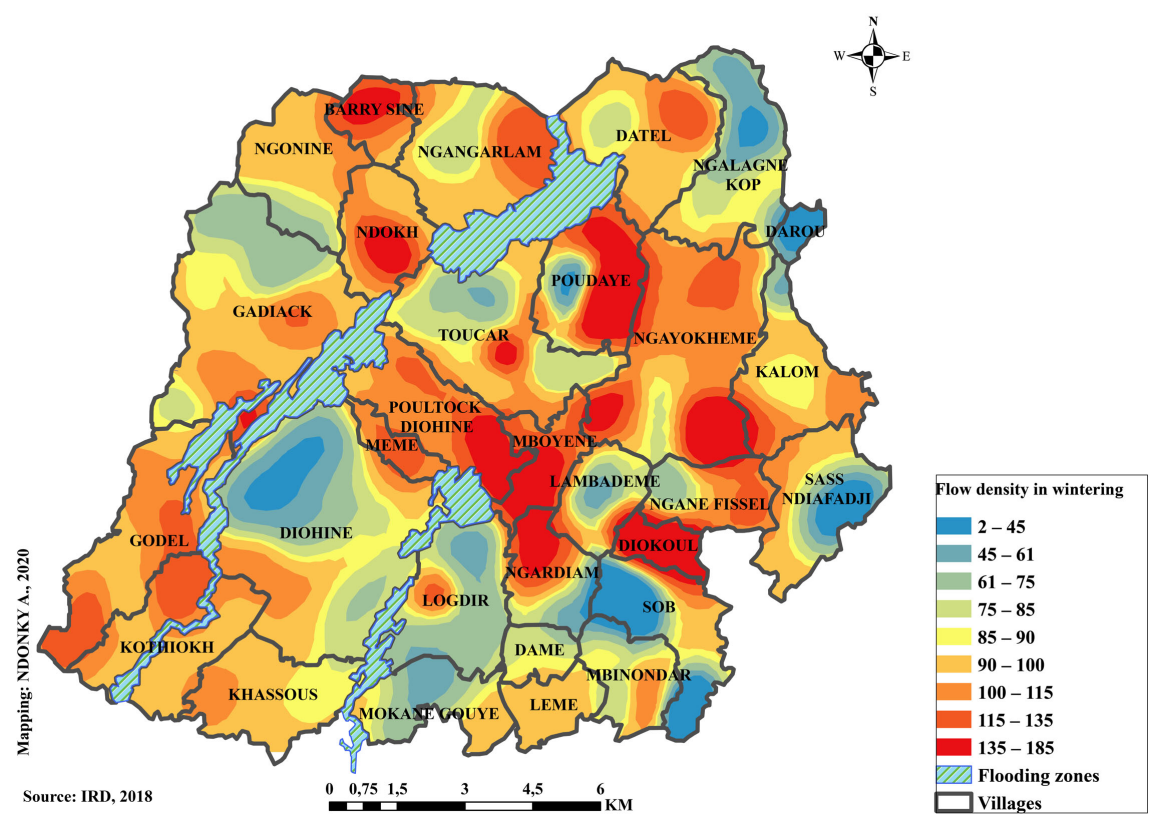

Figure 15. Prediction surface for average flows in the dry season.

the analysis at the village level could not have highlighted. It is the same for the villages of Ngardiam, Toucar, Gadiak, Ngangarlam, ...

Overall, the spatial distribution structure of the flows emitted during wintering is similar to that of the flows emitted in the dry season (Figure 14 and Figure 15). However, there are slight differences related to the intensity of the flux emission in some localities. Thus in the villages of Ngalagne Kop, Logdir and Diohine, the flows emitted in the dry season are more intense than those emitted during the winter. On the other hand, in Kalom, the intensity of the emission of streams is greater in wintering than in the dry season.

\section{Discussion}

Our study revealed the main poles, secondary poles of attraction and repulsive zones, the main sources of emission of intra-zone travel flows in Niakhar. Our results made it possible to highlight the principal directions and the scalar fields of flow (estimated flows in a continuous space). This type of study is a first at the scale of this area, making it difficult to compare its results with those of similar studies in the same area. Nevertheless, we can compare its results with those of studies done elsewhere.

Like other works carried out in various contexts, such as that of [17] on Cameroon, Belgium and Czechoslovakia, by [3] on the agglomeration of Dakar (Senegal), our study highlighted the poles of attraction, the sources of emission flows and the main directions of mobility flows. Unlike the results of the study by [3] which showed a very strong polarization of mobility flows, this study revealed a weaker polarization. This difference is explained by the difference in geographic contexts. Indeed, the agglomeration of Dakar is a peninsula where travel possibilities are limited in certain directions. In addition, this agglomera- 
tion is strongly dominated by a city center which polarizes all trips. On the other hand, the Niakhar area is an open rural environment where the mobility possibilities exist in all directions. In addition, there is not a hyper dominant center that polarizes most of the movement flows.

The main poles of attraction are Toucar, Diohine and Ngayokhème. Those localities also constitute the largest villages which concentrate more population, infrastructure, equipment and services, as well as certain administrative functions such as the Ngayokhème village, capital of the commune of the same name [24]. We can therefore say that the geography of mobility flows is determined by the spatial distribution of infrastructure, basic equipment, economic and social activities, as well as administrative functions.

The results revealed differences in travel practices in the space depending on the season: the volume of travel is greater in the dry season than in wintering and the flows more polarized in wintering than in the dry season. The greater volume of travel in the dry season can be explained by the fact that during this period the populations are done with their field work and have more time to move. Moreover, mobility conditions are easier in the dry season than in the rainy season. In fact, during the rainy season, some localities are cut off from the rest of the area due to the presence of water on the traffic axes. In addition, some roads are in very poor condition. The strongest polarization in wintering may be due to the fact that the possibilities of movement are more limited, because of the difficulties, or even the impossibility of moving on certain traffic axes during this period.

Certainly, we can observe that the level of polarization of travel flows is greater in the outlying villages and weaker in the villages located in the center. This difference should be put into perspective. It is largely linked to the geographical location of these villages. In fact, the villages located on the outskirts emit part of the flows to the neighborhood located outside the study area, but these were not taken into account because of methodological choices (only intra-zones are analyzed). On the other hand, in the villages located in the center, all the flows of movements in the neighborhood were taken into account, whatever the direction.

The advantage of the dominant flow method is that it allows the synthesis of flows. But it has limits, because the dominant flows depend both on the spatial structure of the flows and on the division of the zones, and this can cause difficulties for the comparison of the results. The area interpolation method has the advantage of being able to reveal the spatial variations of the flows within the villages, of being free from the centroids of the irregular meshes to produce the continuous surface. On the other hand, this method eliminates abrupt variations (local pockets of high value of the phenomenon inside the mesh), since it is based on the continuous progression of the density of the workforce [25].

Our study presents some originality compared to those carried out so far in the study area. Indeed, it made it allowed us to map the main mobility flows and to highlight the poles of attraction from a large volume of flows. The use of di- 
rectional statistics helped us to measure the levels of polarization of flows and thus identify the main directions of intra-zone movements. The representation of flows in the form of a continuous surface, from data of areas of irregular shapes and different sizes (villages), also constitutes another originality, because it produced results revealing spatial disparities in mobility, at a spatial resolution very fine.

With the demographic dynamics characterized by the strong growth of the rural population and the neoliberal policies, the spatial disparities of resources become increasingly large even in rural areas. In the specific case of the Niakhar area, large villages tend to be well equipped with basic infrastructure, services and equipment, while smaller localities are under-equipped [24]. Consequently, the inhabitants of the smallest villages are often far from areas of concentration of infrastructure, equipment and services, and forced to travel long distances in order to benefit from the resources located in the dominant villages. This is what the results of our study reveal. Rural mobility is therefore indicative of the functional division of space and resource allocation strategies in rural space.

The spatial characteristics of mobility serve as a basis for defining the spatial allocation of transport infrastructure and equipment [26]. Hence the importance of knowing these characteristics before initiating any reflection on the spatial allocation of transport resources. From this point of view, the results of our study are of definite use, since they can help us highlight the poles of attraction, the sources of emission of the flows, the main directions of movement, as well as the spatial variations in the distribution of emitted fluxes at very fine spatial resolution. Thus we can contribute to the fight against socio-spatial inequalities in mobility practices and access to resources in the rural area.

\section{Conclusions}

The cross-study of dominant centers and flows, vector fields and scalar fields of mobility flows, combining the dominant flow method, directional statistics and the area interpolation method confirms the relevance of our methodological choices, because it has made it possible to better reveal the spatial structure of intra-rural mobility flows, in particular the poles of attraction, the main directions and the scalar fields of flow. This is a significant advance compared to studies carried out so far in the same area.

Our results raise the debate on the relationships between spatial resource allocation policies and spatial segregation in rural areas. With strong demographic growth in rural areas and the lack of regulation of the spatial allocation of basic equipment and infrastructure, rural areas are increasingly segregated, the need for mobility is growing. In this context, spatial and social disparities will tend to increase, to the detriment in particular of populations located in small, isolated and poor villages. We are therefore in a situation which is all the more worrying because the means of collective transport are limited and the public transport systems are poorly organized in rural areas. 
The production of these results is an encouraging first step for the analysis of the spatial structure of intra-rural mobility flows. But improvements need to be made to the methods used to refine the results. Thus, for future studies, socio-demographic characteristics, the location of basic infrastructure and equipment should be taken into account and put in relation to mobility flows. It is also important, to improve the measurement of the scalar field of mobility flows, to introduce a control variable, such as the level of attractiveness measured from the density of infrastructure, services and basic equipment.

Since our approach has been validated in the case of Niakhar, it could, for comparison purposes, be applied to other rural areas in Senegal or Africa.

\section{Conflicts of Interest}

The authors declare no conflicts of interest regarding the publication of this paper.

\section{References}

[1] Crozet, Y. (2009) Les perspectives de la demande de déplacements interurbains. International Transport Forum, Madrid, Discussion Paper, $42 \mathrm{p}$.

[2] Yeo, H., Kra, K.J. and Koffi, L.F.E. (2016) Infrastructures de transport et accessibilité géographique des populations rurales aux équipements sanitaires urbains dans la zone dense de Korhogo (nord de la Côte d'Ivoire). https://doi.org/10.4000/eps.6331

[3] Ndonky, A. and Ndiaye, I. (2016) Cartographie de la mobilité intra-urbaine dans l'agglomération de Dakar. Territoires: Porte d'entrée pour l'émergence durable. Actes du colloque international en 2016 à l'Ecole Supérieure d'Economie Appliquée/Université Cheikh Anta Diop de Dakar.

[4] Tallon, H. (2015) Pauvreté et précarité dans les espaces ruraux: Quelle voie pour une lecture géographique du phénomène? 52ème Colloque ASRDLF, Montpelier, 15 p.

[5] Ndour, D. (2015) Identification des sous-zones de socio-agrosystemes face aux changements globaux dans la zone de niakhar (Sénégal). Mémoire de master, ESEA/UCAD, $125 \mathrm{p}$.

[6] Massot, M.H. and Orfeuil, J.P. (2005) La mobilité au quotidien, entre choix individuel et production sociale. Les Cahiers internationaux de sociologie, No. 118, 81-100. https://doi.org/10.3917/cis.118.0081

[7] Olivera, D.L., Plat, D. and Pochet, P. (1999) Mobilité quotidienne des citadins à faibles ressources. Les enseignements de Ouagadougou. Revue Tiers Monde, 60, 829-848. https://doi.org/10.3406/tiers.1999.5347

[8] Aguilera, A. and Mignot, D. (2003) Polycentrisme et mobilité domicile travail, XXXIXème Colloque de I ASRDLF sur Concentration et ségrégation, dynamiques et inscriptions territoriales, Lyon, 2-3 Septembre 2003, 17 p.

[9] CETUD (2001) Enquête sur la mobilité, le transport et les services urbains a Dakar (EMTSU). 210 p.

[10] CETUD (2014) Préparation d'une expérience pilote d'un système de bus rapides en site propre à Dakar, et de son programme d'investissement. Compléments et actualisation des données contextuelles, Rapport de phase 1, $208 \mathrm{p}$.

[11] Nuysten, J.D. and Dacey, M.F. (1961) A Graph Theory Interpolation of Nodal Re- 
gions. Papers of the Regional Science Association, 7, 29-42. https://doi.org/10.1007/BF01969070

[12] Bahoken, F. (2016) Contribution à la cartographie d'une matrice de flux. Thèse de Doctorat, Univ-Paris 7, Paris, 408 p.

[13] Mardia, K.V. (1975) Statistics of Directional Data (With Discussion). Journal of the Royal Statistical Society. Series B, 37, 349-393. https://doi.org/10.1111/j.2517-6161.1975.tb01550.x

[14] Mardia, K.V. and Jupp, P.E. (2000) Directional Statistics. Wiley, Chichester. https://doi.org/10.1002/9780470316979

[15] Krivoruchko, K., Gribov, A. and Krause, E. (2011) Multivariate Areal Interpolation for Continuous and Count Data. Procedia Environmental Sciences, 3, 14-19. https://doi.org/10.1016/j.proenv.2011.02.004

[16] Delaunay, V., Engeli, E., Franzetti, R., Golay, G., Moullet, A. and Sauvain-Dugerdil, C. (2016) La migration temporaire des jeunes au Sénégal: Un facteur de résilience des sociétés rurales sahéliennes? Afrique Contemporaine, No. 259, 75-94. https://www.cairn.info/revue-afrique-contemporaine-2016-3-page-75.htm https://doi.org/10.3917/afco.259.0075

[17] Bodpa, A., Grasland, C. and Poulain, M. (2000) Evaluation comparative de l'influence des limites linguistiques sur les comportements migratoires. Application au cas de la Belgique, du Cameroun et de la Tchécoslovaquie. In Régimes démographiques et territoires: Les frontières en question, Actes du Colloque international de La Rochelle, 22-26 novembre 1998, PUF, AIDELF, No. 9, 107-124.

[18] Tobler, W.R. (1982) Cartographic Study of Movement Tables, Presentation in the National Computer Graphic Assembly-Session on Statistical Graphics-Mapping, Anaheim, 17-06-1982.

[19] Cattan, N., Grasland, C. and Rehak, S. (1996) Migratory Flows between Czech and Slovak Republics in 1992: Which Forms of Transition? In: Carter, F., Jordan, P. and Rey, V., Eds., Central Europe after the Fall of the Iron Curtain: Geopolitical Perspectives, Spatial Patterns and Trends (Wiener Osteuropastudien, Bd. 4), Peter Lang, Wien, 319-336.

[20] Tobler, Z.R. (1987) Experiments in Migration Mapping by Computer. The American Cartographer, 14, 155-163. https://doi.org/10.1559/152304087783875273

[21] Mitchell, A. (2005) Manuel ESRI d'analyse SIG, Volume 2. ESRI Press, Kuala Lumpur, E-Book. http://www.GIS.com.my

[22] Matheron, G., et al. (1965) Les variables régionalisées et leur estimation. Masson et Cie.

[23] Ribeiro, J.R., Justiniano, P. and Diggle, P.J. (2004) Model Based Geostatistics. Springer Series in Statistics. Springer, Berlin.

[24] Sow, P.B. (2018) Analyse de l'accessibilité géographique aux équipements et la perception des usagers par rapport à l'offre de service au Sénégal: Cas de la zone de Niakhar. Mémoire de master, ESEA/UCAD, 125 p.

[25] Rase, W.D. (2001) Volume-Preserving Interpolation of a Smooth Surface from Polygon-Related Data. Journal for Geographic Systems, 3, 199-213.

https://doi.org/10.1007/PL00011475

[26] Ravalet, E. (2009) Ségrégation urbaine et mobilité quotidienne, une perspective internationale. Études de cas à Niamey, Puebla, Lyon et Montréal, Thèse de doctorat en Sciences économiques, Université Lumière Lyon 2, Lyon, 269 p. 